\title{
Evaluate the priority of product design factors in the process of complex product innovation
}

\author{
Yinyun $\mathrm{Yu}^{1} \mathbb{D} \cdot$ Congdong $\mathrm{Li}^{1}$
}

Received: 6 December 2020 / Accepted: 6 February 2021

(c) The Author(s) 2021

\begin{abstract}
Whether the design of product innovation can highly match the customer demand is the key to extend the product life cycle, and it is also the basis for enterprises to carry out continuous production and operation. The first step of product innovation is to identify the relationship between customer demands and design factors of product innovation. This paper focuses on the problems of market control, due to the wide range and deep level of knowledge from customer demands in the process of product innovation. To better meet the customer demands, combined with Entropy Theorem, Prospect Theory and Grey Correlation Method, this paper puts forward a method of importance of design factors of product innovation considering customer demands. First, the Entropy Theorem and Prospect Theory are introduced to calculate the importance of demand factors from the perspective of customers and experts. Second, the priority ranking of design factors of product innovation from the perspective of customer demand is calculated through Gray Correlation Method and Fuzzy TOPSIS. Finally, this method is availability and feasibility thought taking the continuous innovation of electric vehicle as an example.
\end{abstract}

Keywords Product innovation $\cdot$ Customer demands $\cdot$ Design factors

\section{Introduction}

Product innovation refers to the process of continuously optimizing the function, structure or appearance of the product according to demands. Importance analysis of the design factors of product innovation that considers customer demands mean not only considering the production and operation of the enterprise, but also considering the market demands for the product in the process of product innovation. Customers express their requirements for product functions, structures, appearances, designs to the R\&D department of enterprise. The R\&D department continues to innovate products according to the customer's product demand factors, so that the products can be more encounter the demands of the market and the product life cycle can be extended. In the process of product innovation, it is crucial to effectively identify the relationship between customer demands and design factors [1-3]. Liu WQ believes that companies should design solutions for product innovation

Congdong Li

licd@jnu.edu.cn

1 School of Management, Jinan University, No.601, Huangpu Avenue West, Guangzhou 510632, China based on customer demands and preferences, so as to slow down the speed of product replacement [4]. Yang T believes that product innovation schemes that consider customer satisfaction to have an important impact on the realization of the enterprise's product innovation design goals [5].

In recent years, domestic and foreign scholars have done a lot of research about importance analysis of design factors of product innovation, but most of the research results selected single subject as the research object. In the process of product innovation in reality, we not only need to consider the enterprise's production and management, manufacturing technology, but also consider the diverse and complex demands of customers for products [6,7]. This paper chooses two aspects of enterprise and customers as research subjects, comprehensively considers the influence factors of enterprise and market environments, and establishes the correlation matrix between customer demands and design factors to identify the importance of design factors of product innovation from the dual perspective of "customerenterprise", so as to clarify the direction of product innovation. According to the method proposed in this paper, taking innovation of electric vehicle as the research object, the important priority of design factors of product innovation under customer demands is identified. Importance analysis 
of design factors of product innovation is proposed in this paper, which lays the foundation for the research of importance of design factors of product innovation.

\section{Literature research}

This paper is most related to the literature on customer demands and product innovation.

\section{Customer demand}

The closely relationship between customer demands and continuous product innovation makes it necessary to analyze customer demand factors when analyzing product innovation design factors $[8,9]$. Cho Eun Young studied the impact of product design innovation on consumers' purchase intentions under the influence of environmental awareness, to understand consumers' demand and demand for updated products and proposes marketing strategies [10]. Mancini $\mathrm{M}$ believes that product innovation design should focus on market prediction. Designers should develop an inclusive and humanized innovation vision. Product design should meet customer demands and actively respond to society [11]. Quan HF proposed to combine Kansei Engineering and Kenpi framework to obtain customer demand preferences, and based on convolutional neural network neural style transformation method, inspired product innovation in order to make new product design better meet the needs of users [12]. Kim SJ found product design innovation can increase the perceived value of consumers, which in turn affects consumers' purchasing behavior [13]. Lee S. studied the influence of product form and function design on consumers' purchase behavior. The research found that no matter the degree of product innovation, it has a certain degree of impact on consumer purchase behavior [14]. Blanco T believes that in the context of changing social environment and interpersonal relationship, intelligent electronic product design must fully integrate user demands and technology development. Through 2 years of experimental cases (the first year as the control group), research results has proved the importance of user demands and designers to product innovation [15].

\section{Product innovation}

Identifying the importance of design factors in the process of product innovation is the key to prolonging the production life cycle [16]. The survival of companies depends to a large extent on their ability to innovate products or services [17]. Combining the characteristics of data technology, Xiao RB [18] and Fu L [19] propose a data-driven product innovation design method and elaborated on the role of data-driven in the process of product innovation in terms of demand, design and evaluation. Ko YT proposes a new hybrid compact design matrix based on AD and TRIZ, this paper presents a novel hybrid-compact design matrix. He chose the design of rehabilitation equipment for the elderly as the research object, and verified that this mixed and compact design matrix can really help designers produce more creative results in new product development [20]. Sun HY conducted a data survey of 153 manufacturers in the electronics and electrical appliances industry in China and used structural equation models to analyze the relationship between product development roadmaps and product innovation capabilities [21]. de Bassi Padilha J identified and grouped the elements in the product innovation process, and conducted field research with professional designers to determine the key factors in the product innovation process and their relative importance [22]. Bianchi CG takes the perfume industry as the research object. The research found that innovation ability can be maximized through creative strategies and methods such as co-creation and design thinking, thereby improving product innovation and maximizing the product innovation process [23]. Tania Yehya [24] and Comăniță [25] give a decision analysis to find some key operational parameters.

To satisfy customers' preference for product demand, this paper proposes a method of importance of product innovation design factors considering customer demands. It uses multiple forms of evaluation methods such as accurate number, triangle number, interval number, language term and fuzzy language to collect customer demand preferences, and calculates the relationship between customer demands and design factors by combining Entropy Theorem, Prospect Theory and Grey Correlation method to obtain the importance of design factors of product innovation in the process.

\section{Preliminaries}

The customer's demand for the product directly reflects the customer's purchasing preference and intention. Due to the differences of customers' knowledge background and understanding level, and the diversity of product design factors, it is not scientific to adopt a single form of demand evaluation. This paper takes into account the ambiguity of customer needs and the uncertainty of the evaluation environment and uses a variety of fuzzy evaluation methods to evaluate customer demands, which makes the research results more in line with the actual situation.

As for the demand evaluation of technical indexes such as product hardware configuration and system settings, because customers are limited by their cultural level and professional knowledge, customers can often only give an approximate 
range. This paper uses interval number to collect the evaluation data of such indexes.

Definition 1 [26] If $a=\left[a^{-}, a^{+}\right]$, here $a^{-} \in R, a^{+} \in R$, $a^{-} \leq a^{+}$, we can say $a=\left[a^{-}, a^{+}\right]$is an interval number. Here, $a^{-}$and $a^{+}$denote the lower and upper bounds of interval number. If $a^{-}=a^{+}$, The interval number becomes an exact number, $a=a^{-}=a^{+}$.

$a=\left[a^{-}, a^{+}\right]$and $b=\left[b^{-}, b^{+}\right]$are two interval number, the $\oplus,-, \otimes, \div$ algorithm is as follows:

1. $a \oplus b=\left[a^{-} \oplus b^{-}, a^{+} \oplus b^{+}\right]$

2. $a-b=\left[a^{-}-b^{-}, a^{+}-b^{+}\right]$;

3. $a \otimes b=\left[\min \left(a^{-} b^{-}, a^{-} b^{+}, a^{+} b^{-}, a^{+} b^{-}\right), \max \left(a^{-} b^{-}, a^{-} b^{+}, a^{+} b^{-}, a^{+} b^{-}\right)\right]$;

4. $a \div b=\left[\frac{a^{-}}{b^{+}}, \frac{a^{+}}{b^{-}}\right]$.

For sensitive demand evaluation, indexes such as product prices, customers often give an ideal price. If there is a deviation between the ideal price and the actual selling price of the product, the customer will give an acceptable price range. Both the ideal price and the acceptable price range play a guiding role in the pricing of a enterprise's products, so this paper uses triangular fuzzy numbers to collect evaluation data for such indexes.

Definition 2 [27] If $a=\left(a^{l}, a^{m}, a^{r}\right)$, here $a^{l} \in R, a^{m} \in R$, $a^{r} \in R, a^{l} \leq a^{m} \leq a^{r}$, we can call $a=\left(a^{l}, a^{m}, a^{r}\right)$ is a triangular fuzzy number, which membership function $u_{a}(x)$ is shown in formula (1).

$u_{a}(x)\left\{\begin{array}{c}0, x \leq a^{l} \\ \frac{x-a^{l}}{a^{m}-a^{l}}, a^{l} \leq x \leq a^{m} \\ \frac{a^{r}-x}{a^{r}-a^{m}}, a^{m} \leq x \leq a^{r} \\ 0, a^{r} \leq 0\end{array}\right.$

Here, $a^{l}$ and $a^{r}$ denote the lower and upper bounds of the triangular fuzzy number and $a^{m}$ is the most likely value.

$a=\left(a^{l}, a^{m}, a^{r}\right)$ and $b=\left(b^{l}, b^{m}, b^{r}\right)$ are two triangular fuzzy number, the $\oplus,-, \otimes, \div$ algorithm is as follows:

1. $a \oplus b=\left(a^{l} \oplus b^{l}, a^{m} \oplus b^{m}, a^{r} \oplus b^{r}\right)$;

2. $a-b=\left(a^{l}-b^{l}, a^{m}-b^{m}, a^{r}-b^{r}\right)$;

3. $a \otimes b=\left(a^{l} \otimes b^{r}, a^{m} \otimes b^{m}, a^{r} \otimes b^{l}\right)$;

4. $a \div b=\left(\frac{a^{l}}{b^{r}}, \frac{a^{m}}{b^{m}}, \frac{a^{r}}{b^{l}}\right)$.

Some customer demands for the product may be in a perceptual state. Due to the uncertainty of cognition, customers often use linguistic terms such as "good, better" to evaluate demand indexes. To scientifically quantify the perceptual cognition of customers, this paper combines intuitionistic fuzzy numbers and language terms to collect demand evaluation data for such indexes.

Definition 3 [28] Let $X$ be a given universe of discourse, and the intuitionistic fuzzy number on $X$ is defined a s $\left.\quad a=\left\{<x, u_{a}(x), v_{a}(x)\right\rangle \mid x \in X\right\}, \quad u_{a}(x) \in[0,1]$, $v_{a}(x) \in[0,1][0,1], 0 \leq u_{a}(x)+v_{a}(x) \leq 1 ; u_{a}(x)$ and $v_{a}(x)$ are, respectively, the degree of membership and non-membership of the fuzzy number, and $\pi_{a}(x)$ denotes the degree of hesitation of the fuzzy number, $\pi_{a}(x)=1-u_{a}(x)-v_{a}(x)$. $u_{a}(x), v_{a}(x)$ and $\pi_{a}(x)$, respectively, represent the positive, negative and neutral degree of the object $x$ belonging to the intuitionistic fuzzy number $a$. If $u_{a}(x)=1$ or $v_{a}(x)=1$, the intuitionistic fuzzy number becomes an accurate number.

Definition 4 [29] Let $S$ be the customer perceptual cognitive language term set, $S=\left\{s_{1}, s_{2}, s_{3}, \cdots, s_{n}\right\}$ is the discrete language term set composed of $n$ ordered elements.

The evaluation was conducted using 9-gradient language terms, $S=\left\{s_{1}, s_{2}, s_{3}, s_{4}, s_{5}, s_{6}, s_{7}, s_{8}, s_{9}\right\}$, here $s_{1}=$ Extremely poor,$s_{2}=$ Very poor,$s_{3}=$ Poor , $s_{4}=$ Slightly poor,$s_{5}=$ Middle,$\quad s_{6}=$ Slightly good, $s_{7}=$ Good, $s_{8}=$ Very good, $s_{9}=$ Good. This paper uses the method proposed by Zhang DF [30] to transform linguistic terms into intuitionistic fuzzy values.

In this method, membership $u_{a}(x)$ and non-membership $v_{a}(x)$ of linguistic terms are defined in advance and the evaluator gives the hesitant degree of each evaluation, so as to obtain the interval intuitionistic fuzzy numbers transformed from linguistic terms $\left[u_{a}(x)-\alpha \times \pi_{a}(x), v_{a}(x)-\beta \times \pi_{a}(x)\right]$, $\alpha+\beta=1$. $\alpha$ and $\beta$ denote higher and lower levels of hesitation, respectively. The selection of coefficients for the conversion of language terms into corresponding intuitionistic fuzzy numbers is shown in Table 1.

\section{Problem description}

The length of the product life cycle depends on whether the function of the product meets the demands of market. This paper proposes an analysis method of the importance of continuous product innovation design factors that considers customer demands.

Suppose there are $M$ customer demands for the product in the market, $M=\left(m_{1}, m_{2}, \cdots, m_{n}\right)$. In response to these $M$ customer demands, the enterprise's R\&D team relied on work experience to give $N$ design factors, $N=\left(n_{1}, n_{2}, \cdots, n_{s}\right)$. In response to customer demands $m_{1}$, the enterprise plans to use design factors $n_{1}$ to continuously innovate products; In response to customer demands $m_{2}$, the enterprise plans to use design factors $n_{2}$ to continuously 
Table 1 Language term conversion coefficient table

\begin{tabular}{lll}
\hline Language information & Intuitionistic fuzzy & $\alpha$ and $\beta$ \\
\hline Extremely poor (EP)/Extremely uncorrelation (EU) & $0.1-\alpha \times \pi, 0.1+\beta \times \pi$ & $\alpha=0, \beta=1$ \\
Very poor (VP)/Very uncorrelation (VU) & $0.2-\alpha \times \pi, 0.2+\beta \times \pi$ & $\alpha=0.5, \beta=0.5$ \\
Poor (P)/Uncorrelation (U) & $0.3-\alpha \times \pi, 0.3+\beta \times \pi$ & $\alpha=0.5, \beta=0.5$ \\
Slightly poor(SP)/Slightly uncorrelation (SU) & $0.4-\alpha \times \pi, 0.4+\beta \times \pi$ & $\alpha=0.5, \beta=0.5$ \\
Middle (M)/Middle (M) & $0.5-\alpha \times \pi, 0.5+\beta \times \pi$ & $\alpha=0.5, \beta=0.5$ \\
Slightly good (SG)/Slightly correlation (SC) & $0.6-\alpha \times \pi, 0.6+\beta \times \pi$ & $\alpha=0.5, \beta=0.5$ \\
Good (G)/ Correlation (C) & $0.7-\alpha \times \pi, 0.7+\beta \times \pi$ & $\alpha=0.5, \beta=0.5$ \\
Very good (VG)/Very correlation (VC) & $0.8-\alpha \times \pi, 0.8+\beta \times \pi$ & $\alpha=0.5, \beta=0.5$ \\
Extremely good (EG)/Extremely correlation (EC) & $0.9-\alpha \times \pi, 0.9+\beta \times \pi$ & $\alpha=1, \beta=0$ \\
\hline
\end{tabular}

innovate products. Due to the different intensity of customer demand factors, the importance of design factors is also different. This paper proposes a demand-based multi-angle, multi-subject product innovation design factors importance analysis method. The research process is shown in Fig. 1.

To facilitate the research, some objects involved in the research shall be defined first.
$C d=\left\{C d_{1}, \cdots, C d_{n}\right\}$ is a set of customer demand indexes, where $C d_{i}$ denotes the customer demand for the $i$-th index, $i=1, \cdots, n$.

$P f=\left\{P f_{1}, \cdots, P f_{m}\right\}$ is a set of product design factors, where $P f_{j}$ denotes the product design factor for the $j$-th index, $j=1, \cdots, m$.

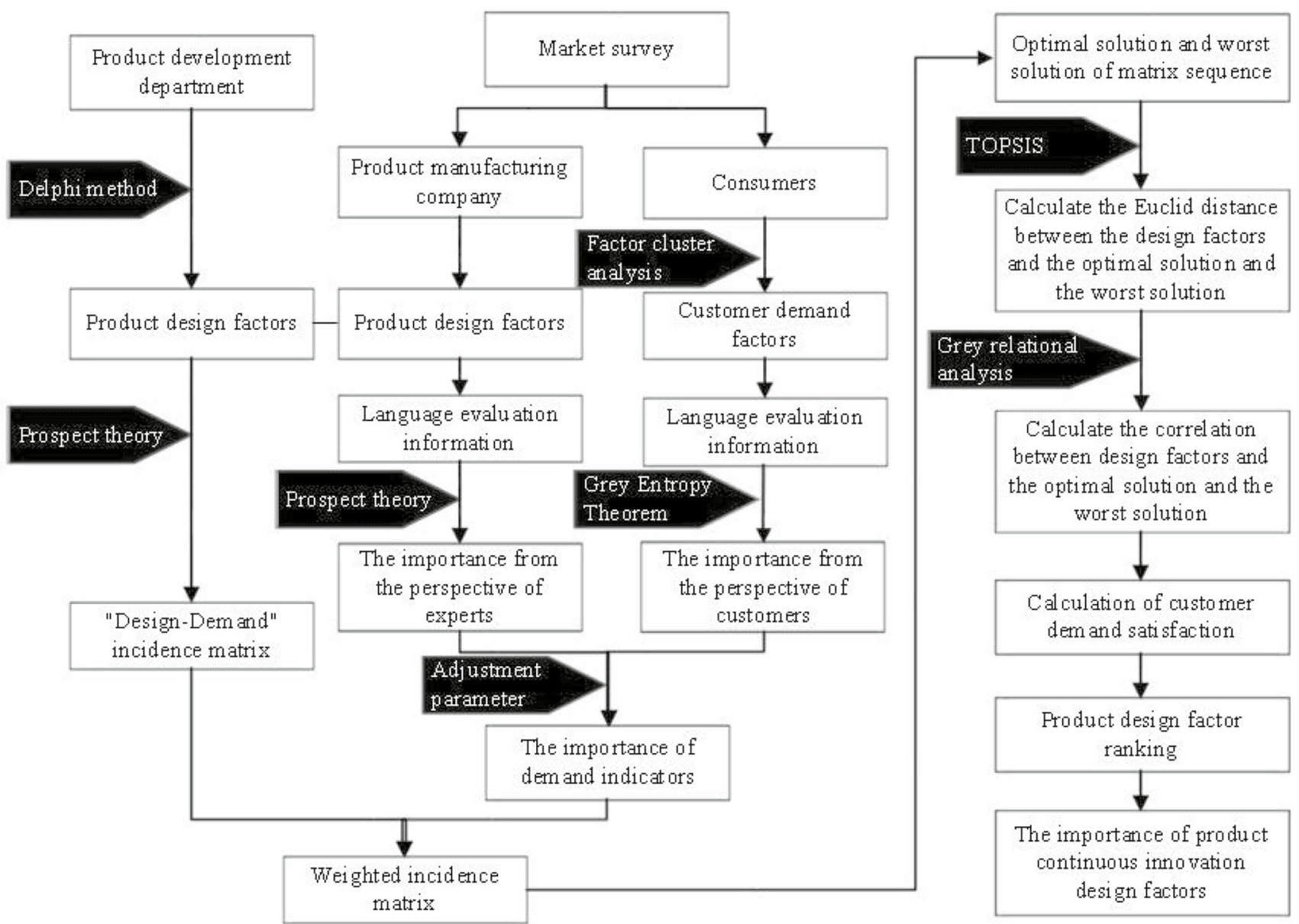

Fig. 1 The flowchart of research 
$R^{t}=\left[R_{1}^{t}, \cdots, R_{m}^{t}\right]^{T}$ is the correlation matrix between customer demands and product design factors, where $R_{1}^{t}=\left[R_{11}^{t}, \cdots, R_{1 n}^{t}\right], \ldots, R_{m}^{t}=\left[R_{m 1}^{t}, \cdots, R_{m n}^{t}\right] ; R_{j i}^{t}$ denotes the correlation between the $i$-th customer demand index and the $j$-th product design factor given by expert $t, i=1, \cdots, n$, $j=1, \cdots, m, t=1,2,3$. In order to make the research results more in line with the actual situation, this paper adopts a multiagent method to determine the correlation between customer demands and product design factors. $R^{1}=\left[R_{1}^{1}, \cdots, R_{m}^{1}\right]^{T}$ denotes the correlation matrix given by the management of the enterprise; $R^{2}=\left[R_{1}^{2}, \cdots, R_{m}^{2}\right]^{T}$ denotes the correlation matrix given by product $\mathrm{R} \& \mathrm{D}$ personnel; $R^{3}=\left[R_{1}^{3}, \cdots, R_{m}^{3}\right]^{T}$ denotes the correlation matrix given by the after-sales personnel.

$D=\left[D_{1}, D_{2}, D_{3}, D_{4}\right]^{T}$ is the customer demand evaluation matrix, where $D_{k i}$ denotes the evaluation value of the $k$-th customer group for the $i$-th customer demand index, $i=1, \cdots, n$, $k=1,2,3,4 ; \quad D_{1}=\left[D_{11}, \cdots, D_{1 n}\right], \quad D_{2}=\left[D_{21}, \cdots, D_{2 n}\right]$, $D_{3}=\left[D_{31}, \cdots, D_{3 n}\right], D_{4}=\left[D_{41}, \cdots, D_{4 n}\right]$. In this paper, four kinds of consumer, including product distributor, salesperson, the representative of the regular customer and new customer, are selected as consumer representatives to evaluate product demands, which makes the demand evaluation results more diverse and comprehensive. $D_{1}$ denotes the demand evaluation given by the product distributor; $D_{2}$ denotes the demand evaluation given by the salesperson; $D_{3}$ denotes the demand evaluation given by the representative of the regular customer; $D_{4}$ denotes the needs evaluation given by the representative of new customer. Due to the customer's expressed preference and product complexity, the evaluation value of customer demand presents accurate number, interval number, triangular fuzzy number and language terms.

\section{Methods}

Satisfying customer demands is the prerequisite of product design, so the analysis of customer needs plays a vital role. This paper first determines the weight of customer demands from the perspective of consumers and experts. On this basis, the "product design factors-customer demands" correlation matrix and demand weights given by the three types of expert groups are integrated to calculated the customer satisfaction of each design factor. In this way, the product innovation design factors are sorted and the importance of the product innovation design factors is finally determined.

\section{Calculation of customer demand importance}

\section{Calculation of demand importance from the perspective of consumers}

This paper selects four kinds of consumer, including product distributor, salesperson, the representative of the regular customer and new customer, are selected as consumer representatives to evaluate product demands, which makes the demand evaluation results more diverse and comprehensive. The higher the score of the demand index, the stronger the customer's demand for the index; the lower the score of the demand index, the weaker the customer's demand for the index. The strength of customer demand determines whether the product can be purchased. Due to the differences in customers' social background and knowledge level, this paper uses a mixed evaluation form to evaluate the demand indexes, so that the evaluation results are more in line with the actual situation. The process of obtaining the importance of demand indexes from the perspective of consumers is as follows:

(1) The demand indexes are evaluated using a variety of evaluation methods such as accurate number, interval number, triangular fuzzy number and language terms.

(2) Standardized data. To eliminate the influence of different dimensions on the importance of demand, the demand evaluation value of the mixed structure is standardized.

If the evaluation value $D_{k i}$ is an accurate value, the normalized formula is as follows:

$D_{k i}^{*}=\frac{D_{k i}}{D_{\max i}}, D_{\max i}=\max \left\{D_{k i} \mid k=1,2,3,4\right\}$.

If the evaluation value $D_{k i}$ is an interval number, the normalized formula is as follows:

$D_{k i}^{\#}=\left[\frac{D_{k i}^{-}}{D_{\max i}^{+}}, \frac{D_{k i}^{+}}{D_{\max i}^{+}}\right], D_{\max i}^{+}=\max \left\{D_{k i}^{+} \mid k=1,2,3,4\right\}$.

If the evaluation value $D_{k i}$ is a triangular fuzzy number, the normalized formula is as follows:

$$
\begin{aligned}
D_{k i}^{*} & =\frac{D_{k i}}{D_{\max i}}=\left(\frac{D_{k i}^{l}}{D_{\max i}^{r}}, \frac{D_{k i}^{m}}{D_{\max i}^{m}}, \frac{D_{k i}^{r}}{D_{\max i}^{l}}\right), D_{\max i} \\
& =\max \left\{D_{k i} \mid k=1,2,3,4\right\} .
\end{aligned}
$$

(3) The importance calculation model is constructed and based on the similarity degree. The closeness degree between the customer evaluation value and the group evaluation value is called the similarity degree. The Grey Correlation Method is used to construct the similarity optimization model as follows:The importance calculation model is constructed and based on the similarity degree. The closeness degree between the customer evaluation value and the group evaluation value 
is called the similarity degree. The Grey Correlation Method is used to construct the similarity optimization model as follows:

$$
\max f_{1}(P)=\sum_{j=1}^{m} \sum_{i=1}^{n} \delta_{k i} P_{i}
$$

s.t. $\left\{\begin{array}{l}\sum_{i=1}^{n} P_{i}=1 \\ 0 \leq P_{i} \leq 1 \\ i=1, \cdots, n .\end{array}\right.$

Here, $P_{i}$ is the initial importance of demand index $C d_{i}$ from the perspective of customers; $\delta_{k i}$ is the correlation degree of demand index $C d_{i}$ between the evaluation value $D_{k i}$ of the $k$-th customer and the group evaluation value $\bar{D}_{* i}$, which can be calculated by formula (7).

$\delta_{k i}=\frac{\min _{k} \min _{i} d\left(D_{k i}, \bar{D}_{* i}\right)+\lambda \max _{k} \max _{i} d\left(D_{k i}, \bar{D}_{* i}\right)}{d\left(D_{k i}, \bar{D}_{* i}\right)+\lambda \max _{k} \max _{i} d\left(D_{k i}, \bar{D}_{* i}\right)}$.

Here, $\lambda$ is the resolution coefficient, $\lambda \in[0,1]$. According to existing literature research, $\lambda$ is often assigned a value of 0.5. $d\left(D_{k i}, \bar{D}_{* i}\right)$ denotes the distance between $D_{k i}$ and $\bar{D}_{* i}$, which can be calculated by formula (8) [31, 32].

$$
d\left(D_{k i}, \bar{D}_{* i}\right)=\left\{\begin{array}{l}
\mid \frac{D_{k i}-\bar{D}_{* i} \mid, D_{k i} \in E N}{\left[\frac{\left(D_{k i}^{-}-\bar{D}_{* i}^{-}\right)^{2}+\left(D_{k i}^{+}-D_{* i}^{+}\right)^{2}}{2}\right]^{\frac{1}{2}}, D_{k i} \in I N} \\
{\left[\frac{\left(D_{k i}^{l}-\bar{D}_{* i}^{l}\right)^{2}+\left(D_{k i}^{m}-\bar{D}_{* i}^{m}\right)^{2}+\left(D_{k i}^{r}-\bar{D}_{* i}^{r}\right)^{2}}{3}\right]^{\frac{1}{3}}, D_{k i} \in T F N}
\end{array}\right.
$$

(4) The importance calculation model is constructed and based on the average degree. The Grey Entropy Theorem is used to construct the calculation model of importance, such as formula $(9,10)[33,34]$. Information entropy has the advantage of strong objectivity, which can minimize the influence of subjectivity on the calculation of information weights in the evaluation process.

Gray entropy $I_{i}$ denotes the average degree of customer demand evaluation and group evaluation. The larger the value of $I_{i}$, the closer the customer demand evaluation is to the group evaluation.

$\max f_{2}(P)=\sum_{i=1}^{n} I_{i} P_{i}$ s.t. $\left\{\begin{array}{c}\sum_{i=1}^{n} P_{i}=1 \\ 0 \leq P_{i} \leq 1 \\ i=1, \cdots, n\end{array}\right.$

Among them, the gray entropy $I_{i}$ can be calculated by formula (11).

$I_{i}=\left\{\begin{array}{l}-\frac{1}{\ln k} \sum_{k=1}^{4} \hat{D}_{k i} \ln \hat{D}_{k i}, D_{k i} \in E N \\ -\frac{1}{\ln k}\left[\hat{D}_{k i}^{-} \ln \hat{D}_{k i}^{-}+\hat{D}_{k i}^{+} \ln \hat{D}_{k i}^{+}\right], D_{k i} \in I N \\ -\frac{1}{\ln k}\left[\hat{D}_{k i}^{l} \ln \hat{D}_{k i}^{l}+\hat{D}_{k i}^{m} \ln \hat{D}_{k i}^{m}+\hat{D}_{k i}^{r} \ln \hat{D}_{k i}^{r}\right], D_{k i} \in T F N\end{array}\right.$

Here $\hat{D}_{k i}=\frac{D_{k i}}{\sum_{k=1}^{4} D_{k i}}, \hat{D}_{k i}^{-}=\frac{\hat{D}_{k i}^{-}}{\sum_{k=1}^{4} \hat{D}_{k i}^{-}}, \ldots, \hat{D}_{k i}^{m}=\frac{\hat{D}_{k i}^{m}}{\sum_{k=1}^{4} \hat{D}_{k i}^{m}}$.

(5) Considering the similarity degree and average degree, the importance degree of demand indexes from the perspective of customers is calculated as follows

$\max f_{c}(P)=\sum_{k=1}^{4} \sum_{i=1}^{n} \delta_{k i} P_{i}+\sum_{i=1}^{n} I_{i} P_{i}$

s.t. $\left\{\begin{array}{c}\sum_{i=1}^{n} P_{i}=1 \\ 0 \leq P_{i} \leq 1 \\ i=1, \cdots, n\end{array}\right.$

Through formulas $(12,13)$, we can get that the importance of the demand indexes from the perspective of the customer is $P=\left(P_{1}, P_{2}, \cdots, P_{n}\right)$.

\section{Calculation of demand importance from the perspective of experts}

The close connection between product design and customer demands is a prerequisite for sustainable development of an enterprise. Considering the customer demand from the perspective of experts, it shows the attribute bias of product design. If experts attach great importance to a demand, it will be given priority in product design. At the beginning of product design, it is difficult to determine the satisfaction degree of product for each demand factor, so it is often described by language terms. Linguistic terms also conform to the linguistic expression habits of experts in a fuzzy environment. The process of obtaining the importance of demand indexes from the perspective of experts is as follows.

(1) Prospect Theory can well express people's judgment and decision-making under uncertain circumstances [35]. This paper uses Prospect Theory to describe the attribute bias of experts in product design. The larger 
the value of the prospect, the more important the experts pay attention to the demands of this aspect. The importance model of expert design preference customer demand based on prospect theory is as follows:

$\max f\left(Z^{t}\right)=\sum_{j=1}^{m} \sum_{i=1}^{n} \vartheta_{j i}^{t} Z_{i}^{t}$

s.t. $\left\{\begin{array}{c}\sum_{i=1}^{n} Z_{i}^{t}=1 \\ 0 \leq Z_{i}^{t} \leq 1 ; \\ t=1,2,3 .\end{array}\right.$

Here, $Z_{i}^{t}$ is the initial importance of demand index $C d_{i}$ from the perspective of the $t$-th expert; $\vartheta_{j i}^{t}$ is the prospect value of $R_{j i}^{t}$ and $R_{i}^{*}$, which can be calculated by formula (16).

$\vartheta_{j i}^{t}=\left\{\begin{array}{c}\left(d\left(R_{j i}^{t}, R_{i}^{*}\right)\right)^{\mu}, R_{j i}^{t} \geq R_{i}^{*} \\ -\rho\left(d\left(R_{j i}^{t}, R_{i}^{*}\right)\right)^{v}, R_{j i}^{t}<R_{i}^{*}\end{array}\right.$

Through formulas $(14,15,16)$, we can get that the importance of the demand indexes from the perspective of the $t$-th expert is $Z_{i}^{t}=\left(Z_{1}^{t}, Z_{2}^{c}, \cdots, Z_{n}^{c}\right)$.

(2) The larger the prospect value $\vartheta_{j i}^{t}$ of the $t$-th expert, the closer the product design preference of the $t$-th expert is to the attributes of customer demands, the greater the weight of the $t$-th expert. The weight of the $t$-th expert can be obtained by formula (17).

$Q_{t}=\frac{\vartheta_{j i}^{t}}{\sum_{t=1}^{3} \vartheta_{j i}^{t}}$

(3) Based on the Prospect Theory, the importance of customer demands is obtained from the perspective of experts.

$Z_{i}=\sum_{t=1}^{3} Z_{i}^{t} Q_{t}$

According to formula (18), the importance of the demand index from the perspective of experts is $Z=\left(Z_{1}, Z_{2}, \cdots, Z_{n}\right)$.

\section{The ultimate importance of customer needs}

The importance of customer demand indexes includes the importance of the consumer's perspective and the expert's perspective. The importance from the consumer's perspective reflects the direct customer demands for the product.
The importance from the perspective of experts reflects the tendency of experts' demands in product design. The comprehensive weighting method is used to introduce adjustment parameter $\xi$ to determine the importance of customer demands, $0 \leq \xi \leq 1$. According to the production and operation experience, the enterprise selects the appropriate adjustment parameter value.

$\omega_{i}=\xi P_{i}+(1-\xi) Z_{i}$

Here, $\omega_{i}$ denotes the importance of the $i$-th customer demand.

\section{Calculation of importance of product design factors}

With the increase of customer demands, product design has become complex. Satisfying customer demands to the greatest extent is the fundamental guarantee for a product to extend its life cycle. Therefore, effectively identifying the relationship between customer demands and product design factors has become a research hotspot in recent years. According to customer demands, product design corresponds to market demands to the greatest extent. The process of calculating the importance of product design factors is as follows.

(1) Calculation of weighted incidence matrix. According to the incidence matrix $R$ given by experts and the customer importance calculated by formula (19), the weighted incidence matrix $\tilde{R}$ is obtained by formulas $(20,21)$.

$\tilde{R}=\omega R$

$\tilde{R}_{j i}=\omega_{i} R_{j i}$

(2) The optimal value and the worst value. For benefit indicators, the larger the indicator value, the better; For cost-based indicators, the smaller the indicator value, the better. According to the weighted incidence matrix $\tilde{R}$, we can get the optimal value and the worst value of each demand index.

$G^{b}=\left(\tilde{R}_{1}^{b}, \tilde{R}_{2}^{b}, \cdots, \tilde{R}_{n}^{b}\right), \tilde{R}_{i}^{b}=\max _{1 \leq j \leq m}\left\{\tilde{R}_{j i}^{b}\right\}$

$G^{w}=\left(\tilde{R}_{1}^{w}, \tilde{R}_{2}^{w}, \cdots, \tilde{R}_{n}^{w}\right), \tilde{R}_{i}^{w}=\min _{1 \leq j \leq m}\left\{\tilde{R}_{j i}^{w}\right\}$

Here, $G^{b}$ and $G^{w}$ denote the optimal value and the worst value. 
(3) Calculating the distance between the product design factors and the optimal value and the worst value [33].

$$
\begin{aligned}
& d_{j}^{b}=\sum_{i=1}^{n} d\left(\tilde{R}_{j i}, \tilde{R}_{i}^{b}\right) \\
& d\left(\tilde{R}_{j i}, \tilde{R}_{i}^{b}\right)=\left[\frac{\left(\tilde{R}_{j i}^{-}-\tilde{R}_{i}^{b-}\right)^{2}+\left(\tilde{R}_{j i}^{+}-\tilde{R}_{i}^{b+}\right)^{2}}{2}\right]^{\frac{1}{2}} \\
& d_{j}^{w}=\sum_{i=1}^{n} d\left(\tilde{R}_{j i} \tilde{R}_{i}^{w}\right) \\
& d\left(\tilde{R}_{j i}, \tilde{R}_{i}^{w}\right)=\left[\frac{\left(\tilde{R}_{j i}^{-}-\tilde{R}_{i}^{w-}\right)^{2}+\left(\tilde{R}_{j i}^{+}-\tilde{R}_{i}^{w+}\right)^{2}}{2}\right]^{\frac{1}{2}}
\end{aligned}
$$

(4) The incidence matrix of design factors and customer demands. According to the Grey Correlation Method, the correlation coefficient $H_{j i}$ between each product design factor and the optimal value and the worst value is calculated [36, 37]. For better scientific research, we first defuzzify the interval intuitionistic fuzzy number, and the calculation formula is as follows.

$\dot{\tilde{R}}=\frac{\tilde{R}^{-}+\tilde{R}^{+}}{2}$

$H_{j}^{+}=\frac{\min _{1 \leq j \leq m} \min _{1 \leq i \leq n}\left|\dot{\tilde{R}}_{j i}-\dot{\tilde{R}}_{i}^{+}\right|+\lambda \max _{1 \leq j \leq m} \max _{1 \leq i \leq n}\left|\dot{\tilde{R}}_{j i}-\dot{\tilde{R}}_{i}^{+}\right|}{\left|\dot{\tilde{R}}_{j i}-\dot{\tilde{R}}_{i}^{+}\right|+\lambda \max _{1 \leq j \leq m} \max _{1 \leq i \leq n}\left|\dot{\tilde{R}}_{j i}-\dot{\tilde{R}}_{i}^{+}\right|}$

$H_{j}^{-}=\frac{\min _{1 \leq j \leq m} \min _{1 \leq i \leq n}\left|\dot{\tilde{R}}_{j i}-\dot{\tilde{R}}_{i}^{-}\right|+\lambda \max _{1 \leq j \leq m} \max _{1 \leq i \leq n}\left|\dot{\tilde{R}}_{j i}-\dot{\tilde{R}}_{i}^{-}\right|}{\left|\dot{\tilde{R}}_{j i}-\dot{\tilde{R}}_{i}^{-}\right|+\lambda \max _{1 \leq j \leq m} \max _{1 \leq i \leq n}\left|\dot{\tilde{R}}_{j i}-\dot{\tilde{R}}_{i}^{-}\right|}$

Among them, $\lambda$ is the resolution coefficient, $\lambda \in[0,1]$. According to existing literature research, $\lambda$ is often assigned a value of 0.5 .

(5) Ranking of product design factors. According to the formulas $(24,25,26,27,28)$, the distance and correlation coefficient between the product design factors and the optimal value and the worst value are obtained, and using formulas $(29,30)$ to normalize them.

$\ddot{d}_{j}^{b}=\frac{d_{j}^{b}}{\sum_{j=1}^{m} d_{j}^{b}}, \ddot{d}_{j}^{w}=\frac{d_{j}^{w}}{\sum_{j=1}^{m} d_{j}^{w}}$
$\ddot{H}_{j}^{+}=\frac{H_{j}^{+}}{\sum_{j=1}^{m} H_{j}^{+}}, \ddot{H}_{j}^{-}=\frac{H_{j}^{-}}{\sum_{j=1}^{m} H_{j}^{-}}$

The key design factor should have the smallest distance from the optimal value, the largest distance from the worst value, the largest correlation with the optimal value, and the smallest correlation with the worst value. According to the previous research, the distance and the degree of association are both non-negative numbers. Based on this, establish the satisfaction degree of each product design factor for customer demands [36].

$\max U=\sum_{j=1}^{m}\left[\left(1-\Phi_{j}\right) \ddot{d}_{j}^{w} \ddot{H}_{j i}^{+}\right]^{2}+\sum_{j=1}^{m}\left(\Phi_{j} \ddot{d}_{j}^{b} \ddot{H}_{j}^{-}\right)^{2}$

Take the derivative of (31), that is, let $\frac{d\left(U_{j}\right)}{d\left(\Phi_{i}\right)}=0$.

$\Phi_{j}=\frac{\left(\ddot{d}_{j}^{w} \ddot{H}_{j}^{+}\right)^{2}}{\left(\ddot{d}_{j}^{w} \ddot{H}_{j}^{+}\right)^{2}+\left(\ddot{d}_{j}^{b} \ddot{H}_{j}^{-}\right)^{2}}$

The product design factors are sorted according to relative satisfaction degree. The larger the $\Phi_{j}$, the more important the product design factors.

\section{Example analysis}

E enterprise produces pure electric vehicles in W city. To optimize resource allocation and meet customer needs, the enterprise now plans to improve the poorly sold MAT-2 pure electric vehicles. After-sales interviews are conducted with E enterprise product distributors, sales staff, the representatives of regular customer and new customer to screen out the top eight demands that the customer groups care about most, which are battery capacity $\left(C d_{1}\right)$, product price $\left(C d_{2}\right)$, safety configuration $\left(C d_{3}\right)$, battery life $\left(C d_{4}\right)$, charging time $C d_{5}\left(C d_{5}\right)$, seat comfort $\left(C d_{6}\right)$, body length $\left(C d_{7}\right)$, power output $\left(C d_{8}\right)$.

According to customer demands, selecting enterprise management (three people), product R\&D personnel (eight people) and after-sales personnel (five people) to form an expert group, and using the brainstorming method to obtain seven designs factors that are most closely related to the eight customer demands, which are power supply $\left(P f_{1}\right)$, drive motor $\left(P f_{2}\right)$, airbag device $\left(P f_{3}\right)$, vehicle control $\left(P f_{4}\right)$, load setting $\left(P f_{5}\right)$, chassis setting $\left(P f_{6}\right)$, soft installation setting $\left(P f_{7}\right)$.

According to the attribute of demand indexes and the expression of customer groups, a questionnaire was designed and distributed to 4 types of customer groups with 150 
copies for each type. Using interval number to evaluate demand index $C d_{1}$; using triangular fuzzy number to evaluate demand indexes $C d_{3}, C d_{5}, C d_{7}$; using language terms to evaluate demand indexes $C d_{3}, C d_{4}, C d_{8}$; using accurate number to evaluate demand indexes $C d_{6}$. According to the knowledge background and expression preference of the expert group, linguistic terms are used to evaluate the correlation $R$ between product design factors and customer demands. Based on this, we can obtain the mean matrix of demand evaluation given by the customer group and the expert group as shown in Table 2 and the mean matrix of the correlation given by the expert group as shown in Table 3 .

According to the method described in this paper and Table 4, the importance of demand indexes from the perspective of customers is obtained by using formulas (5)-(13), which is $P=(0.128,0.160,0.131,0.112,0.115,0.110,0.112,0.131)$; according to Table 5 and formulas (14)-(18), the importance of demand indexes from the perspective of experts is obtained, which is
$Z=(0.152,0.184,0.113,0.108,0.097,0.130,0.076,0.141)$. According to the production and operation experience, the enterprise introduces the adjustment parameter $\xi=0.6$ and determines the importance of customer demand as $\omega=(0.137,0.169,0.124,0.110,0.108,0.118,0.097,0.135)$ according to formula (19). Drawing $P, Z$ and $\omega$ in Fig. 2, it can be seen clearly that $C R_{2}$ has the highest demand degree from the perspective of customers and experts.

The mean value of the correlation given in Table 5 is calculated to obtain the mean correlation value of the expert group, and the weighted incidence matrix $\tilde{R}$ is obtained according to formulas $(20,21)$, as shown in Table 6 .

According to the index attribute and the weighted incidence matrix shown in Table 6 , the maximum sequence and minimum sequence of each column in the incidence matrix are extracted which is the optimal value and the worst value of each demand index as follows.

Table 2 Customer demands evaluation value

\begin{tabular}{lllllllll}
\hline & $C d_{1}$ & $C d_{2}$ & $C d_{3}$ & $C d_{4}$ & $C d_{5}$ & $C d_{6}$ & $C d_{7}$ & $C d_{8}$ \\
\hline$D_{1}$ & {$[305,450]$} & $(25,32,35)$ & $\mathrm{M}(0.2)$ & $\mathrm{SP}(0.2)$ & $(4.000,5.000,6.000)$ & 50 & $(3.800,4.000,4.300)$ & $\mathrm{M}(0.2)$ \\
$D_{2}$ & {$[378,500]$} & $(20,28,32)$ & $\mathrm{SP}(0.3)$ & $\mathrm{M}(0.1)$ & $(5.500,6.000,7.000)$ & 72 & $(4.000,4.300,4.600)$ & $\mathrm{G}(0.2)$ \\
$D_{3}$ & {$[300,450]$} & $(21,27,30)$ & $\mathrm{G}(0.1)$ & $\mathrm{M}(0.2)$ & $(5.000,6.500,7.500)$ & 62 & $(4.000,4.500,4.800)$ & $\mathrm{VG}(0.1)$ \\
$D_{4}$ & {$[355,500]$} & $(19,25,34)$ & $\mathrm{G}(0.2)$ & $\mathrm{G}(0.2)$ & $(6.000,7.000,8.000)$ & 54 & $(4.200,4.600,5.000)$ & $\mathrm{VG}(0.2)$ \\
$\bar{D}$ & {$[335,475]$} & $(21,28,33)$ & $\mathrm{SG}(0.2)$ & $\mathrm{M}(0.2)$ & $(5.125,6.125,7)$ & 60 & $(4.000,4.350,4.675)$ & $\mathrm{M}(0.3)$ \\
\hline
\end{tabular}

Table 3 The correlation of product design factors and demands (Taking $R^{1}$ as an example)

\begin{tabular}{lllllllll}
\hline & $C d_{1}$ & $C d_{2}$ & $C d_{3}$ & $C d_{4}$ & $C d_{5}$ & $C d_{6}$ & $C d_{7}$ & $C d_{8}$ \\
\hline$R^{1}$ & & & & & & & & \\
$P f 1$ & $\mathrm{VC}(0.2)$ & $\mathrm{C}(0.1)$ & $\mathrm{VU}(0.2)$ & $\mathrm{VC}(0.1)$ & $\mathrm{VC}(0.2)$ & $\mathrm{EU}(0.1)$ & $\mathrm{C}(0.3)$ & $\mathrm{VC}(0.2)$ \\
$P f 2$ & $\mathrm{SC}(0.1)$ & $\mathrm{VC}(0.1)$ & $\mathrm{SU}(0.3)$ & $\mathrm{C}(0.2)$ & $\mathrm{M}(0.3)$ & $\mathrm{VU}(0.2)$ & $\mathrm{C}(0.1)$ & $\mathrm{VC}(0.1)$ \\
$P f 3$ & $\mathrm{VU}(0.1)$ & $\mathrm{C}(0.2)$ & $\mathrm{VC}(0.1)$ & $\mathrm{VU}(0.1)$ & $\mathrm{VU}(0.1)$ & $\mathrm{M}(0.1)$ & $\mathrm{C}(0.1)$ & $\mathrm{U}(0.2)$ \\
$P f 4$ & $\mathrm{M}(0.2)$ & $\mathrm{VC}(0.2)$ & $\mathrm{M}(0.1)$ & $\mathrm{M}(0.2)$ & $\mathrm{SU}(0.3)$ & $\mathrm{VU}(0.4)$ & $\mathrm{VU}(0.2)$ & $\mathrm{M}(0.2)$ \\
$P f 5$ & $\mathrm{EC}(0.3)$ & $\mathrm{VC}(0.2)$ & $\mathrm{SU}(0.3)$ & $\mathrm{VC}(0.1)$ & $\mathrm{VC}(0.2)$ & $\mathrm{SU}(0.3)$ & $\mathrm{VU}(0.2)$ & $\mathrm{VC}(0.1)$ \\
$P f 6$ & $\mathrm{SC}(0.1)$ & $\mathrm{SC}(0.3)$ & $\mathrm{SC}(0.1)$ & $\mathrm{VU}(0.1)$ & $\mathrm{M}(0.2)$ & $\mathrm{SC}(0.3)$ & $\mathrm{M}(0.1)$ & $\mathrm{VC}(0.2)$ \\
$P f 7$ & $\mathrm{VU}(0.1)$ & $\mathrm{U}(0.2)$ & $\mathrm{VU}(0.3)$ & $\mathrm{VU}(0.1)$ & $\mathrm{EU}(0.1)$ & $\mathrm{VC}(0.2)$ & $\mathrm{VC}(0.1)$ & $\mathrm{VU}(0.1)$ \\
\hline
\end{tabular}

According to formulas $(2,3)$, Tables 2 and 3 are normalized to obtain Tables 4 and 5

Table 4 Customer demands evaluation standard value

\begin{tabular}{llllllllll}
\hline & $C d_{1}$ & $C d_{2}$ & $C d_{3}$ & $C d_{4}$ & $C d_{5}$ & $C d_{6}$ & $C d_{7}$ & $C d_{8}$ \\
\hline$D_{1}$ & {$[0.228,0.237]$} & $(0.136,0.286,0.576)$ & {$[0.201,0.222]$} & {$[0.171,0.204]$} & $(0.195,0.204,0.390)$ & 0.210 & $(0.171,0.230,0.320)$ & {$[0.170,0.197]$} \\
$D_{2}$ & {$[0.263,0.283]$} & $(0.109,0.250,0.527)$ & {$[0.132,0.204]$} & {$[0.224,0.257]$} & $(0.245,0.268,0.455)$ & 0.303 & $(0.180,0.247,0.342)$ & {$[0.213,0.230]$} \\
$D_{3}$ & {$[0.224,0.237]$} & $(0.115,0.241,0.494)$ & {$[0.278,0.342]$} & {$[0.229,0.245]$} & $(0.244,0.265,0.455)$ & 0.261 & $(0.180,0.259,0.357)$ & {$[0.279,0.319]$} \\
$D_{4}$ & {$[0.261,0.263]$} & $(0.104,0.223,0.560)$ & {$[0.296,0.316]$} & {$[0.327,0.343]$} & $(0.286,0.293,0.520)$ & 0.227 & $(0.189,0.264,0.372)$ & {$[0.295,0.298]$} \\
$\bar{D}$ & {$[0.244,0.255]$} & $(0.116,0.250,0.539)$ & {$[0.500,0.700]$} & {$[0.400,0.600]$} & $(0.243,0.258,0.455)$ & 0.25 & $(0.180,0.250,0.348)$ & {$[0.350,0.650]$}
\end{tabular}


Table 5 The standard values of correlation (Taking $R^{1}$ as an example)

\begin{tabular}{lllllllll}
\hline & $C d_{1}$ & $C d_{2}$ & $C d_{3}$ & $C d_{4}$ & $C d_{5}$ & $C d_{6}$ & $C d_{7}$ & $C d_{8}$ \\
\hline$R^{1}$ & & & & & & & & \\
$P f 1$ & {$[0.7,0.9]$} & {$[0.65,0.75]$} & {$[0.1,0.3]$} & {$[0.75,0.85]$} & {$[0.7,0.9]$} & {$[0.1,0.2]$} & {$[0.55,0.85]$} & {$[0.7,0.9]$} \\
$P f 2$ & {$[0.55,0.65]$} & {$[0.75,0.85]$} & {$[0.25,0.55]$} & {$[0.6,0.8]$} & {$[0.35,0.65]$} & {$[0.1,0.3]$} & {$[0.65,0.75]$} & {$[0.75,0.85]$} \\
$P f 3$ & {$[0.15,0.25]$} & {$[0.6,0.8]$} & {$[0.75,0.85]$} & {$[0.15,0.25]$} & {$[0.15,0.25]$} & {$[0.45,0.55]$} & {$[0.65,0.75]$} & {$[0.2,0.4]$} \\
$P f 4$ & {$[0.4,0.6]$} & {$[0.7,0.9]$} & {$[0.45,0.55]$} & {$[0.4,0.6]$} & {$[0.25,0.55]$} & {$[0,0.4]$} & {$[0.1,0.3]$} & {$[0.4,0.6]$} \\
$P f 5$ & {$[0.6,0.9]$} & {$[0.7,0.9]$} & {$[0.25,0.55]$} & {$[0.75,0.85]$} & {$[0.7,0.9]$} & {$[0.25,0.55]$} & {$[0.1,0.3]$} & {$[0.75,0.85]$} \\
$P f 6$ & {$[0.55,0.65]$} & {$[0.45,0.75]$} & {$[0.55,0.65]$} & {$[0.15,0.25]$} & {$[0.4,0.6]$} & {$[0.45,0.75]$} & {$[0.45,0.55]$} & {$[0.7,0.9]$} \\
$P f 7$ & {$[0.15,0.25]$} & {$[0.2,0.4]$} & {$[0.05,0.35]$} & {$[0.15,0.25]$} & {$[0.1,0.2]$} & {$[0.7,0.9]$} & {$[0.75,0.85]$} & {$[0.15,0.25]$} \\
\hline
\end{tabular}

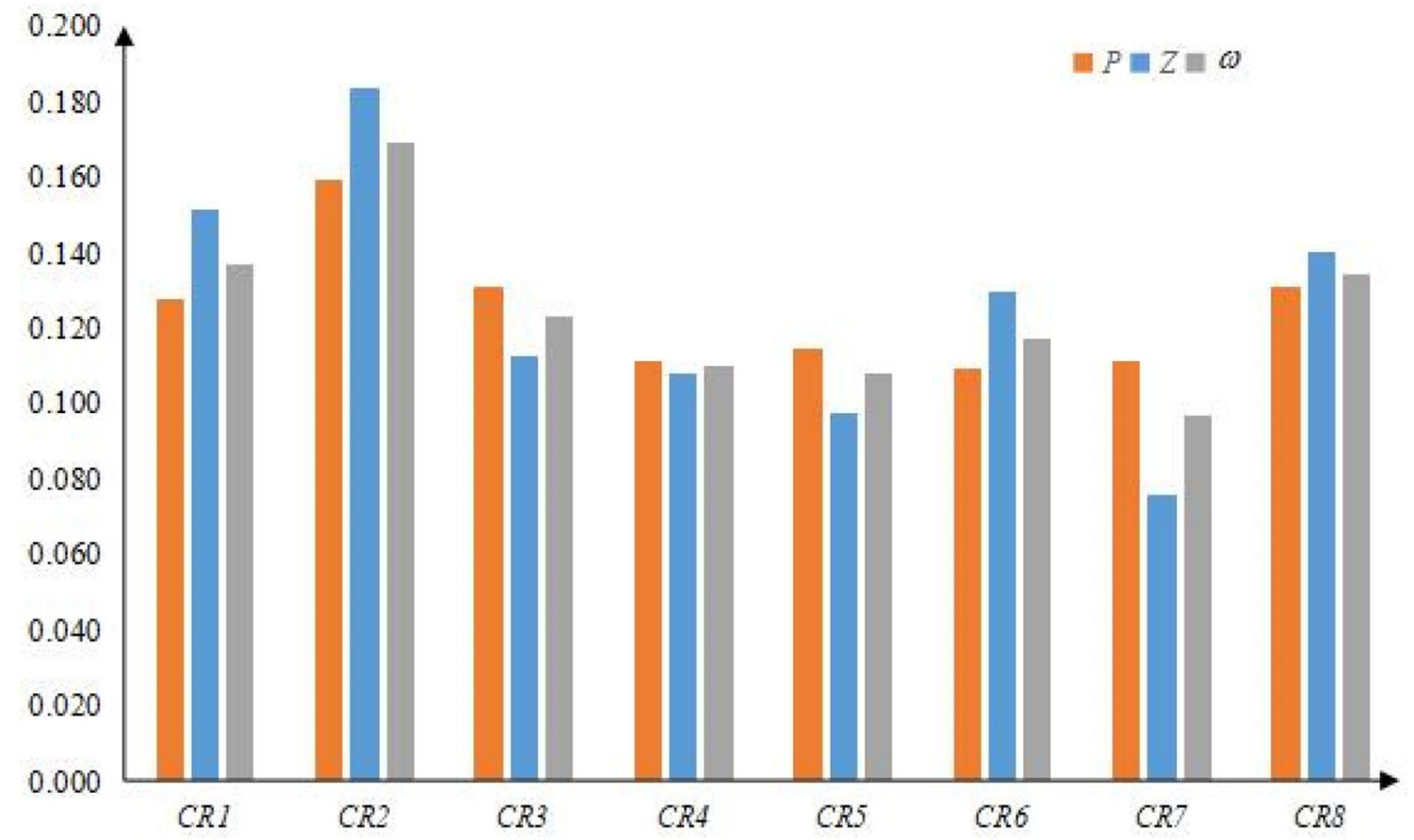

Fig. 2 The importance of demand indexes

Table 6 The value of the weighted incidence matrix

\begin{tabular}{lllllllll}
\hline & $C d_{1}$ & $C d_{2}$ & $C d_{3}$ & $C d_{4}$ & $C d_{5}$ & $C d_{6}$ & $C d_{7}$ & $C d_{8}$ \\
\hline$\tilde{R}$ & & & & & & & & \\
& & & & & & & \\
$P f 1$ & {$[0.103,0.121]$} & {$[0.090,0.124]$} & {$[0.029,0.054]$} & {$[0.077,0.092]$} & {$[0.081,0.095]$} & {$[0.012,0.031]$} & {$[0.047,0.070]$} & {$[0.092,0.115]$} \\
$P f 2$ & {$[0.087,0.114]$} & {$[0.121,0.138]$} & {$[0.033,0.066]$} & {$[0.057,0.090]$} & {$[0.049,0.074]$} & {$[0.014,0.033]$} & {$[0.042,0.062]$} & {$[0.099,0.117]$} \\
$P f 3$ & {$[0.016,0.039]$} & {$[0.110,0.138]$} & {$[0.093,0.105]$} & {$[0.018,0.033]$} & {$[0.013,0.027]$} & {$[0.043,0.067]$} & {$[0.055,0.068]$} & {$[0.020,0.043]$} \\
$P f 4$ & {$[0.055,0.082]$} & {$[0.121,0.155]$} & {$[0.062,0.086]$} & {$[0.053,0.079]$} & {$[0.013,0.063]$} & {$[0.018,0.053]$} & {$[0.018,0.041]$} & {$[0.063,0.090]$} \\
$P f 5$ & {$[0.087,0.110]$} & {$[0.088,0.127]$} & {$[0.058,0.082]$} & {$[0.074,0.088]$} & {$[0.063,0.088]$} & {$[0.025,0.053]$} & {$[0.021,0.044]$} & {$[0.094,0.112]$} \\
$P f 6$ & {$[0.048,0.071]$} & {$[0.088,0.116]$} & {$[0.076,0.097]$} & {$[0.029,0.051]$} & {$[0.031,0.056]$} & {$[0.051,0.075]$} & {$[0.042,0.062]$} & {$[0.088,0.110]$} \\
$P f 7$ & {$[0.027,0.046]$} & {$[0.048,0.088]$} & {$[0.012,0.045]$} & {$[0.013,0.028]$} & {$[0.011,0.029]$} & {$[0.084,0.104]$} & {$[0.070,0.080]$} & {$[0.018,0.031]$} \\
\hline
\end{tabular}


$G^{b}=\left(\begin{array}{c}{[0.103,0.121],[0.048,0.088],[0.093,0.105],[0.077,0.092],} \\ {[0.011,0.029],[0.084,0.104],[0.070,0.080],[0.099,0.117]}\end{array}\right)$

$G^{w}=\left(\begin{array}{l}{[0.016,0.039],[0.121,0.155],[0.012,0.045],[0.013,0.028],} \\ {[0.081,0.095],[0.012,0.031],[0.018,0.041],[0.018,0.031]}\end{array}\right)$

The distance between the product design factors and the optimal value and the worst value is calculated by using the formulas $(24,25)$; The correlation between the product

Table 7 The distance and correlation between the product design factors and customer demands

\begin{tabular}{lllll}
\hline & $\ddot{d}_{j}^{b}$ & $\ddot{d}_{j}^{w}$ & $\ddot{H}_{j}^{+}$ & $\ddot{H}_{j}^{-}$ \\
\hline$\tilde{R}$ & & & & \\
$P f 1$ & 0.133 & 0.150 & 0.164 & 0.145 \\
$P f 2$ & 0.141 & 0.145 & 0.151 & 0.145 \\
$P f 3$ & 0.169 & 0.116 & 0.134 & 0.141 \\
$P f 4$ & 0.166 & 0.130 & 0.137 & 0.143 \\
$P f 5$ & 0.125 & 0.159 & 0.151 & 0.145 \\
$P f 6$ & 0.115 & 0.168 & 0.135 & 0.144 \\
$P f 7$ & 0.150 & 0.132 & 0.127 & 0.137 \\
\hline & & & &
\end{tabular}

design factors and customer demands is calculated using the formulas $(26,27,28)$; The dimensionless treatment was carried out by formulas $(29,30)$, the results are shown in Table 7.

According to the formulas $(31,32)$, the satisfaction degrees of each product design factor to customer demands are $P f_{1}=0.619, P f_{2}=0.534, P f_{3}=0.298, P f_{4}=0.360$, $P f_{5}=0.637, P f_{6}=0.652$ and $P f_{7}=0.400$, respectively. The satisfaction degree of each product design factor to customer demand is drawn in the line chart, as shown in Fig. 3. We can get the ranking of product design factors is $P f_{6}>P f_{5}>P f_{1}>P f_{2}>P f_{7}>P f_{4}>P f_{3}$, that is, in the process of continuous innovation of electric vehicle products, the R\&D personnel of $E$ enterprise paid the highest attention to the chassis setting, followed by the load setting, power supply, drive motor, soft installation setting, vehicle control, and airbag device is the lowest.

\section{Discussion}

Customer demands have a major impact on the ranking of the importance of product innovation and design factors.
Fig. 3 The satisfaction degrees of each product design factor to customer demands

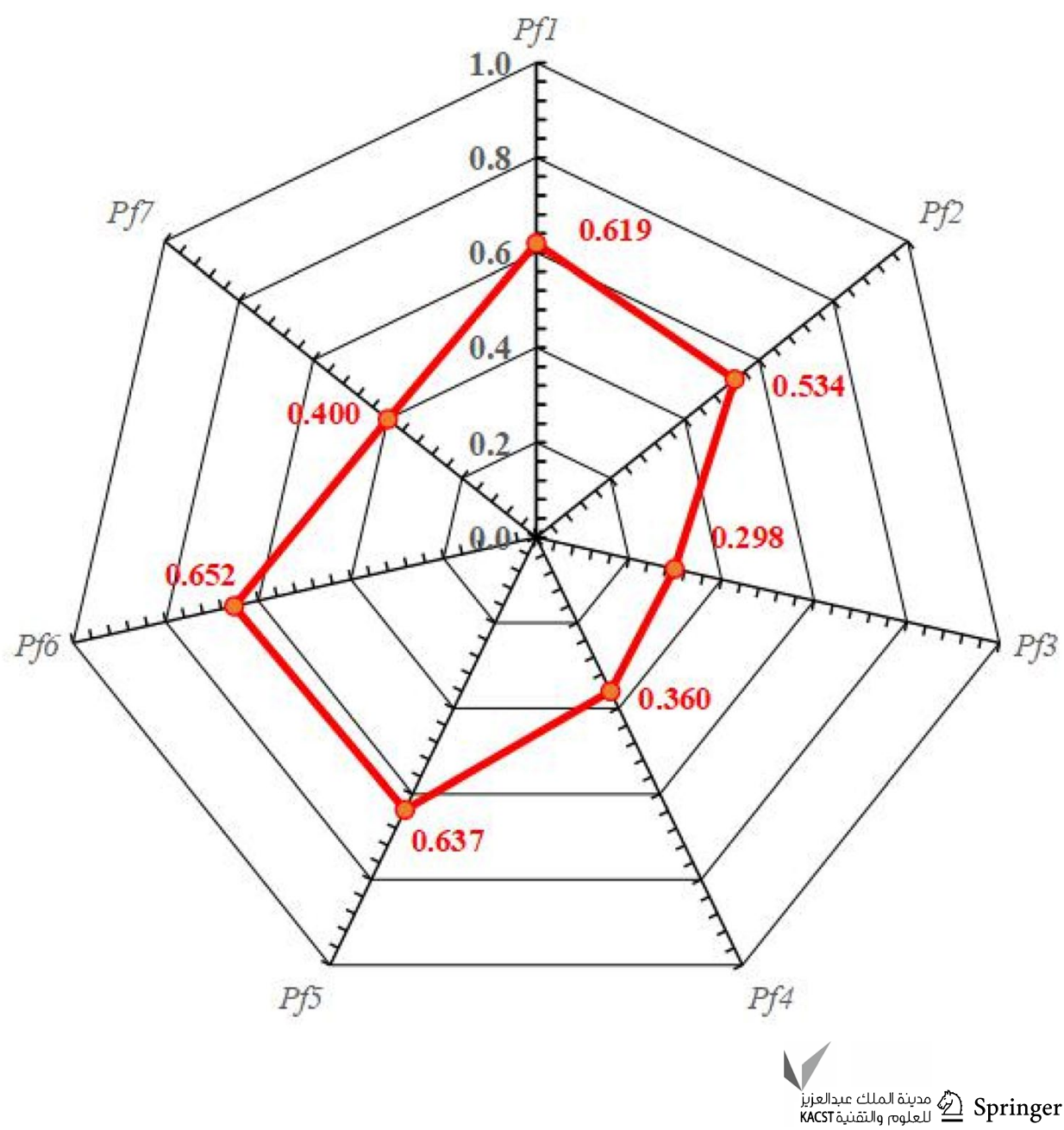




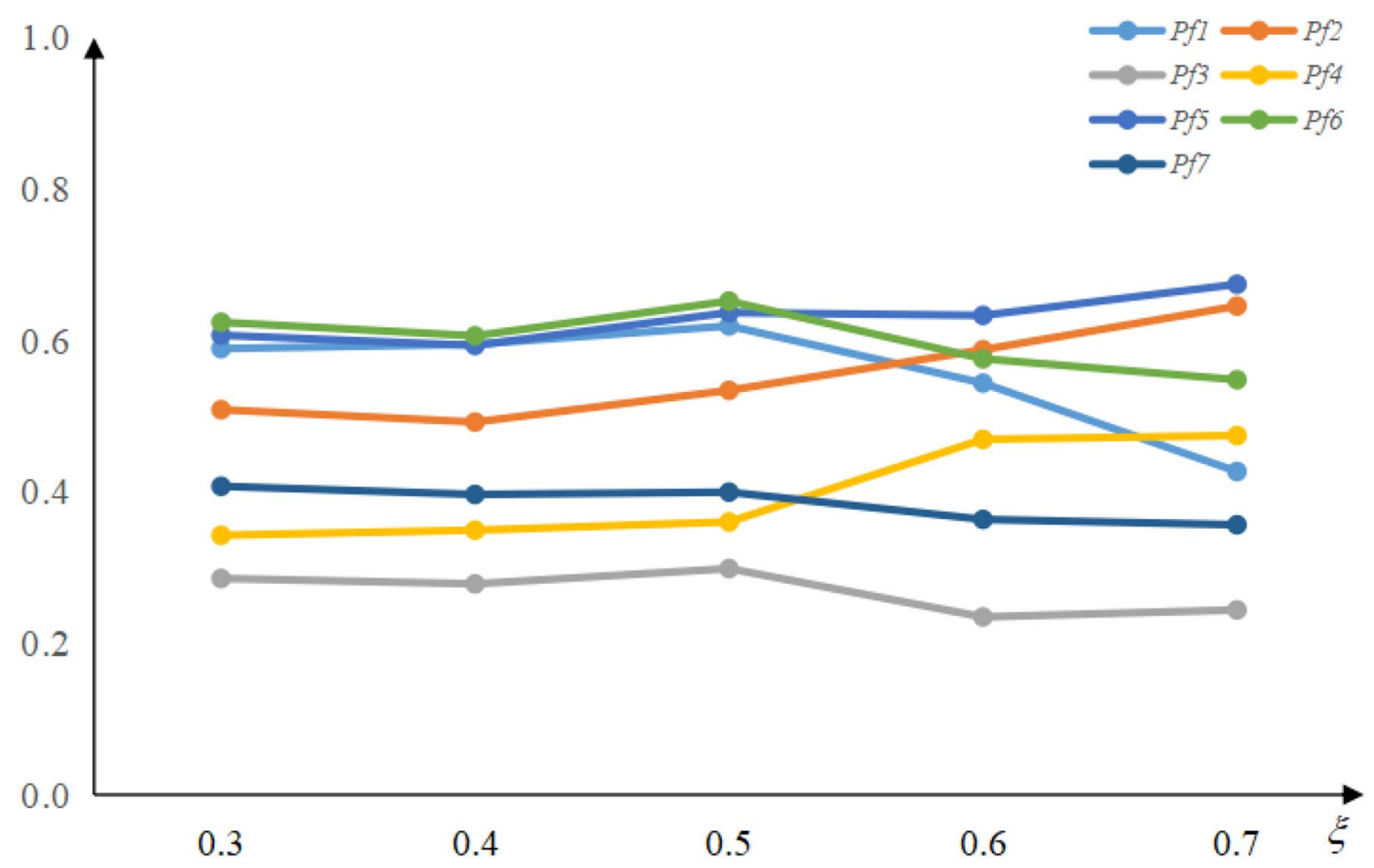

Fig. 4 The importance ranking of design factors at different values of $\xi$

Considering the enterprise's preference for accepting customer opinions and expert opinions, the sensitivity analysis of adjustment parameters $\xi$ is carried out to determine the importance ranking of product innovation design factors under different conditions, $0 \leq \xi \leq 1$. Figure 4 shows the ranking result of the importance of design factors when $\xi$ takes different values.

From the above figure, we can see that when $\xi \in[0.3,0.5]$, the importance of design factors changes little; when $\xi \in[0.5,0.7]$, the importance of design factors changes significantly. This shows that when enterprise focus on customer opinions for product innovation, enterprise can get a good importance ranking of design factors. Design factors are more sensitive to changes in demand factors from the perspective of customers. Therefore, in the process of product innovation, enterprise need to consider customer demands more in order to obtain accurate product innovation orientation.

\section{Conclusion}

Customer demands are an important factors that guide companies in continuous product innovation and have an important impact on the realization of the enterprise's production experience and the extension of the product life cycle. This paper studies the importance analysis of design factors for product innovation and proposes a ranking method for the importance of design factors, which comprehensively considers customer demands and enterprise manufacturing technology. This paper first considers the expression preferences of customers and experts, and adopts multiple forms of evaluation methods such as accurate number, triangle number, interval number, linguistic term and fuzzy language, so as to minimize the lack of evaluation information and improve the accuracy of evaluation results; Second, this paper analyzes the design factors of product innovation from the perspective of customers and experts, enriches the evaluation angle and subject, and makes the ranking result more suitable for market demands. The importance analysis method of product innovation design factors proposed in this paper is reasonable in logic and clear in structure. It lays the foundation for the subsequent analysis of relevant product innovation factors and provides direction for enterprises to carry out continuous product innovation design.

Due to the limitation of knowledge and the difficulty of data collection, this paper does not subdivide the customer groups. In the future research work, we can give priority to subdivide the customer groups, and then consider the 
customer demand preferences of subdivided groups, so as to make the products more meet the needs of the market.

Acknowledgements The authors would like to acknowledge partial financial support from National Natural Science Foundation of China (71672074), National Natural Science Foundation of China (72072072), Natural Science Foundation of Guangdong Province of China (2019A1515010045), 2018 Guangzhou Leading Innovation Team Program (China) (201909010006). The second author is the corresponding author for this study.

Data availability The data used to support the findings of this study are available from the corresponding author upon request.

\section{Compliance with ethical standards}

Conflict of interest The authors declare that they have no conflicts of interest.

Open Access This article is licensed under a Creative Commons Attribution 4.0 International License, which permits use, sharing, adaptation, distribution and reproduction in any medium or format, as long as you give appropriate credit to the original author(s) and the source, provide a link to the Creative Commons licence, and indicate if changes were made. The images or other third party material in this article are included in the article's Creative Commons licence, unless indicated otherwise in a credit line to the material. If material is not included in the article's Creative Commons licence and your intended use is not permitted by statutory regulation or exceeds the permitted use, you will need to obtain permission directly from the copyright holder. To view a copy of this licence, visit http://creativecommons.org/licenses/by/4.0/.

\section{References}

1. Shin Y, Im C, Oh H, Kim J (2017) Design for experience innovation: understanding user experience in new product development. Behav Inform Technol 36(12):1218-1234

2. Ocampo LA (2015) A hierarchical framework for index computation in sustainable manufacturing. Adv Prod Eng Manag 10(1):40-50

3. Koren R, Palčič I (2015) The impact of technical and organisational innovation concepts on product characteristics. Adv Prod Eng Manag 10(1):27-39

4. Liu WQ, Zhang JW, Jiang XY, Hao HN (2019) Linguistic multiattribute decision-making evaluation method for product innovation design scheme with demand preferences of customers. Int J Intell Syst 23(3):211-218. https://doi.org/10.3233/KES-190413

5. Yang T, Yang Y, Zhang DD (2015) Generation of product innovation conceptual design schemes for considering the demand preferences of customers. CIMS 21(4):875-884

6. Aydin H (2020) Market orientation and product innovation: the mediating role of technological capability. Eur J Innov Manag. https ://doi.org/10.1108/EJIM-10-2019-0274

7. Xu W, Liu LN, Zhang QS, Liu P (2018) Location decision-making of equipment manufacturing enterprise under dual channel purchase and sale mode. Complexity. https://doi.org/10.1155/2018/3797131

8. Liu W, Moultrie J, Ye SH (2019) The customer-dominated innovation process: involving customers as designers and decision-makers in developing new product. Desing J 22(3):299-324

9. Ongus RW, Nyamboga CM (2019) Collecting development practices in using information technology: a comparative study. J Logist Inform Serv Sci 6(2):1-22
10. Young CE, SoYoung L (2018) Impact of design innovation on purchasing intention of up-cycling products. IJRDM 21(5):141-150. https://doi.org/10.17961/jdmr.21.5.201810.141

11. Mancini M (2017) A contemporary didactics of innovation in product design. Grip Factors identification and evaluation. Design J 20:732-744

12. Quan HF, Li SB, Hu JJ (2018) Product innovation design based on deep learning and kansei engineering. Appl Sci-Basel 8(12):1-17

13. Kim SJ, Kim KH, Choi J (2019) The role of design innovation in understanding purchase behavior of augmented products. J Bus Res 99:354-362

14. Lee S, Johnson ZS (2017) The effect of new product design and innovation on South Korean consumer's willingness to buy. Asia Pac J Mark Logist 29(1):11-98

15. Blanco T, Casas R, Manchado-Perez E, Asensio A, Lopez-Perez JM (2017) From the islands of knowledge to a shared understanding: interdisciplinarity and technology literacy for innovation in smart electronic product design. Int J Technol Des Ed 27(2):329-362. https ://doi.org/10.1007/s10798-015-9347-7

16. Ashoka K, Shanmugathas S (2018) Factors influencing the mark-up decisions of infrastructure projects in developing countries: the case of Sri Lanka. J Syst Manag Sci 8(2):1-25

17. Dias ASME, Abreu A, Navas HVG, Santos R (2020) Proposal of a Holistic Framework to Support Sustainability of New Product Innovation Processes. Sustainability 12(8):1-18

18. Xiao RB, Lin WG (2019) Research on data-driven product innovation design. STM J 36(12):1-9

19. Fu L, Dong Y (2018) Research on internet search data in China's social problems under the background of big data. J Logist Inform Serv Sci 5(2):55-67

20. Ko YT (2017) Modeling a hybrid-compact design matrix for new product innovation. Comput Ind Eng 107:345-359

21. Sun HY, Lau A (2019) The impact of modular design and innovation on new product performance. The role of product newness. J Manuf Technol Mana 31(2):370-391

22. de Bassi PJ, Cziulik C, de Camargo BPA (2017) Vectors of innovation definition for application during conceptual design stage of product development process. JOTMI 12(1):49-60

23. Bianchi CG, dos Santos AB, Borini FM (2018) Open innovation and co-creation in the development of new products: the role of design thinking. IJI 6(2):112-123

24. Yehya T, Favier L, Kadmi Y, Audonnet F, Fayad N, Gavrilescu M, Vial C (2015) Removal of carbamazepine by electrocoagulation: investigation of some key operational parameters. Environ Eng Manag J 14:639-645

25. Comăniță E, Cozma P, Simion I, Roșca M, Gavrilescu M (2018) Evaluation of eco-efficiency by multicriteria decision analysis. case study of eco-innovated and eco-designed products from recyclable waste. Environ Eng Manag J 17:1791-1804

26. Sun G, Xia WL (2016) Evaluation method for innovation capability and efficiency of high technology enterprises with interval-valued intuitionistic fuzzy information. J Intell Fuzzy Syst 31(3):1419-1425

27. Seresht NG, Fayek AR (2019) Computational method for fuzzy arithmetic operations on triangular fuzzy numbers by extension principle. Int J Approx Reason 106:172-193. https://doi.org/10.1016/j. ijar.2019.01.005

28. Li HY, Xu W, Zhang YY, Wu TT (2020) Evaluation of factors influencing the sustainable development of the marine equipment manufacturing industry cluster. J Coast Res 106(sp1):440-444

29. Li ZR, Xu W, Shi HB, Zhang QS, He FY (2019) Multiobjective optimization model of production planning in cloud manufacturing based on TOPSIS method with combined weights. Complexity. https ://doi.org/10.1155/2019/7503176

30. Zhang DF, Zhang JL, Lai KK, Lu YB (2009) An novel approach to supplier selection based on vague sets group decision. Expert Syst Appl 36(5):9557-9563

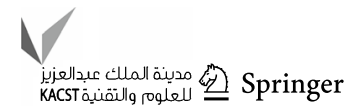


31. Pei JY, Shan P (2019) A multi-objective hybrid differential optimization algorithm for flow-shop scheduling problem. Int J Simul Model 18(3):500-509

32. Vrecko I, Kovac J, Rupnik B, Gajsek B (2019) Using queuing simulation model in production process innovations. Int J Simul Model 18(1):47-58

33. Zhang QS, Deng J, Shao Y (1995) A grey correlational analysis by the method of degree of balance and approach. J Huazhong Univ Sci-Med 11:94-98

34. Matar I (2018) The integration of knowledge management into the lebanese graphic design business sector. J Syst Manag Sci $8(1): 61-82$

35. Su N, Zhu XQ, Xin YS (2020) Using improved prospect theory to develop a partner selection method for virtual enterprises with unknown weight. Math Probl Eng. https://doi. org/10.1155/2020/9608704

36. Zhang L, Li JT, Zhao YY, Tian ZQ (2020) Evaluation method for product design based on users'emotional needs. Oper Res Manag Sci 28(1):152-157

37. Xie JM, Qin Q, Jiang MT (2020) Multi-objective decision-making for technical characteristics selection in a house of quality. Math Probl Eng. https://doi.org/10.1155/2020/9243142

Publisher's Note Springer Nature remains neutral with regard to jurisdictional claims in published maps and institutional affiliations. 